\title{
On the use of ground-based synthetic aperture radar for long-term slope monitoring to support the mine geotechnical team
}

\author{
L Leoni IDS Ingegneria Dei Sistemi SpA, Italy \\ N Coli IDS Ingegneria Dei Sistemi SpA, Italy \\ P Farina IDS Ingegneria Dei Sistemi SpA, Italy \\ F Coppi IDS Ingegneria Dei Sistemi SpA, Italy
}

A Michelini IDS Ingegneria Dei Sistemi SpA, Italy

TA Costa Vale S.A., Brazil

TAV Costa Vale S.A., Brazil

F Costa IDS Brasil, Brazil

\begin{abstract}
Nowadays, ground-based synthetic aperture radar interferometry (GBInSAR) is used internationally as a leading edge tool for the near real time monitoring of slope movements on landslides and open pit mines for both safety-critical or background monitoring purposes. The success of the technology relies mainly on its ability to rapidly measure slope movements with sub-millimetre accuracy over wide areas and in almost any weather condition. In this paper an advanced data processing chain able to simultaneously measure a wide range of deformation rates, across four orders of magnitudes, from moderate movements (up to $150 \mathrm{~mm} /$ hour) to extremely low displacements (few $\mathrm{mm} / \mathrm{month}$ ), is presented. The use of this processing for long-term monitoring may result in an early detection of slow movements and eventually the setup of remedial before they start to interfere with operations or problems become too difficult or expensive to be managed. The advantages and site experiences are presented along with recent successful studies in several Brazilian iron ore mines with different characteristics, owned by Vale S.A. In the sites radar data have been integrated and compared to displacement measurements acquired by traditional monitoring systems, in order to improve the interpretation of the local slope movements and predict failure mechanisms. This technique is now applied to support long-term monitoring, adding to the traditional systems to provide the necessary reliability, coverage and safety.
\end{abstract}

\section{Introduction}

In the open pit mines, a comprehensive slope monitoring program should aim to manage potential large-scale instabilities and also be able to detect small scale movements. Among all the parameters to be considered and included in an effective slope monitoring program displacements, either surface or sub-surface components, play a crucial role. In open pit mines, large failures are usually preceded by small scale slope movements, sometimes limited to a few centimetres of displacement and typically characterised by temporal evolutions ranging from several hours to several weeks or months. The capability of providing advanced notice over the whole slope of impending instability, through the accurate and timely measurement of precursors to slope collapses, clearly represents an outstanding benefit for the team responsible for the management of geotechnical risk. The use of ground-based synthetic aperture radar (GBInSAR) in open pit mines is today a standard practice for safety critical monitoring of the pit walls. SAR radar units are effectively used to get a better understanding of the spatial distribution of slope movements and for the provision of alerts in the event of progressive movements that can potentially lead to slope failure, thus aimed at ensuring the safety of workers and increasing mine productivity. 
Early detection of ground deformations allows the geotechnical team to predict and possibly avoid failure. GBInSAR radar technology presents the advantages of high measurement accuracy, long-range capability, limited impact of atmospheric artefacts, and the possibility to simultaneously acquire the response over a large area of the slope without reducing the acquisition time (Antonello et al. 2004; Bozzano et al. 2011; Farina et al. 2011; 2013; Pieraccini 2013).

The long datasets typically acquired by GBInSAR systems installed in open pit mines (years of continuous data) have made it possible to measure very slow movements. This is possible due to the long range and resulting ability to monitor pit slopes without relocating the radar during blasting, as well as the capability to reinstall the equipment in the last same position in order to continue monitoring. Such a possibility allows the use of slope monitoring radar not only to measure fast movements but also slow movements.

Here we present some results from Vale's mine monitoring applications of the advanced data processing algorithms developed by the authors. The algorithms are able to simultaneously measure a wide range of displacement rates, across four orders of magnitudes, from fast-moderate movements (up to $150 \mathrm{~mm} /$ hour) to extremely low displacements (few $\mathrm{mm} / \mathrm{month}$ ), with very high accuracy $(0 \pm 0.1 \mathrm{~mm})$. These advanced capabilities offer to a new concept of radar monitoring, where radar also becomes a valuable source of information to better understand the slope behaviour before failure mechanisms start interacting with mining operations. Early recognition of ground movements allows review of extraction techniques, mine design and ground support before the instability becomes too difficult or expensive to mitigate. Vale's iron ore geotechnical team have successfully implemented advanced monitoring based on the IBIS radar GBInSAR, not only for fast movements but also for slow movements. In these sites radar data have been integrated and compared to displacement measurements acquired by total stations in order to improve the interpretation of the ground instability issues.

\section{$2 \quad$ GBInSAR for long-term slope monitoring}

A ground-based SAR system with interferometric capabilities is characterised by a limited number of moving parts, being composed of a radar sensor with a couple of small horn antennas that illuminate the monitored area while sliding along a short rail (Pieraccini 2013). Modern GBInSAR systems perform a full resolution scan of the observed area in a short time (e.g. less than 3 minutes). Fast scan time means reduced impact of atmospheric variations atmospheric conditions on radar data and higher sensitivity to the onset of potential failure. The radar used in Vale mines described in this paper are IBIS-FM units. IBIS radar is produced by the Italian company IDS (Farina et al. 2011).

The introduction of GBInSAR systems into the mining industry from 2010, thanks to its longer working range (resulting in wider spatial coverage) combined with its fast acquisition, made it possible to revolutionise the typical application of slope monitoring radar, passing from a 'tactical' use focused on critical areas to a combined and joint 'strategic' and 'tactical' use. A further recent advance in the use of slope monitoring radar is associated with the capabilities of GBInSAR to acquire long datasets in combination with innovative processing algorithms to extend the measurable velocity by those systems, including not only moderate movements (e.g. $\mathrm{mm} /$ day, $\mathrm{cm} /$ day) but also very slow movements ( $\mathrm{mm} / \mathrm{month}, \mathrm{mm} /$ year). Any device aimed at measuring displacement can measure it only when the total displacement substantially exceeds the noise level of the instrument. Considering the typical accuracy of GBInSAR systems $(0.1 \pm 0.1 \mathrm{~mm})$, it follows that in order to detect slow movements it is necessary to consider long time intervals in order to give enough time for the movement to exceed the measurement noise. This concept can be easily explained by referring to the interferograms (the maps showing the raw phase variation, which is proportional to the total displacement) extracted from a radar dataset and presented in Figure 1. 


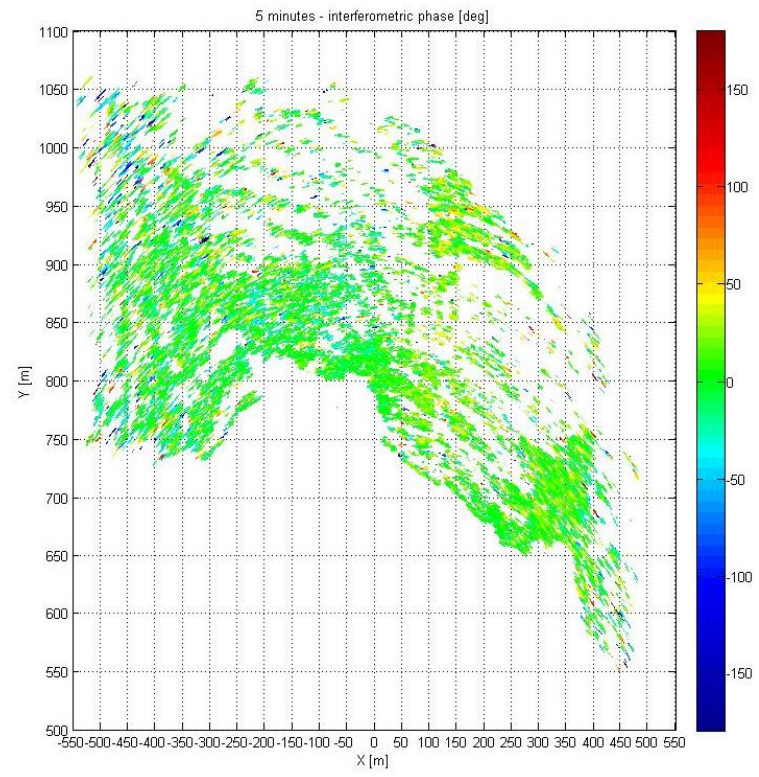

(a)

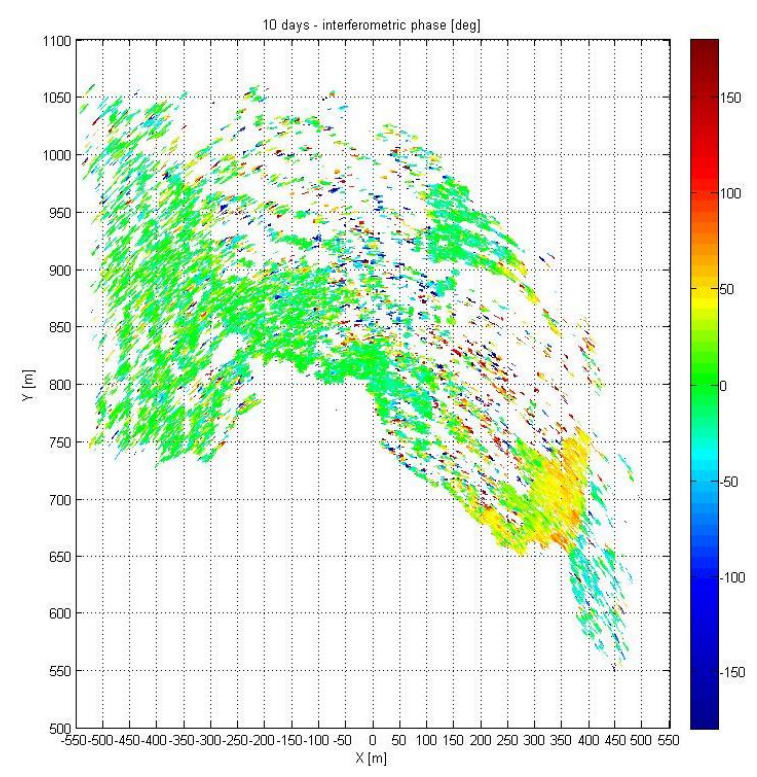

(c)

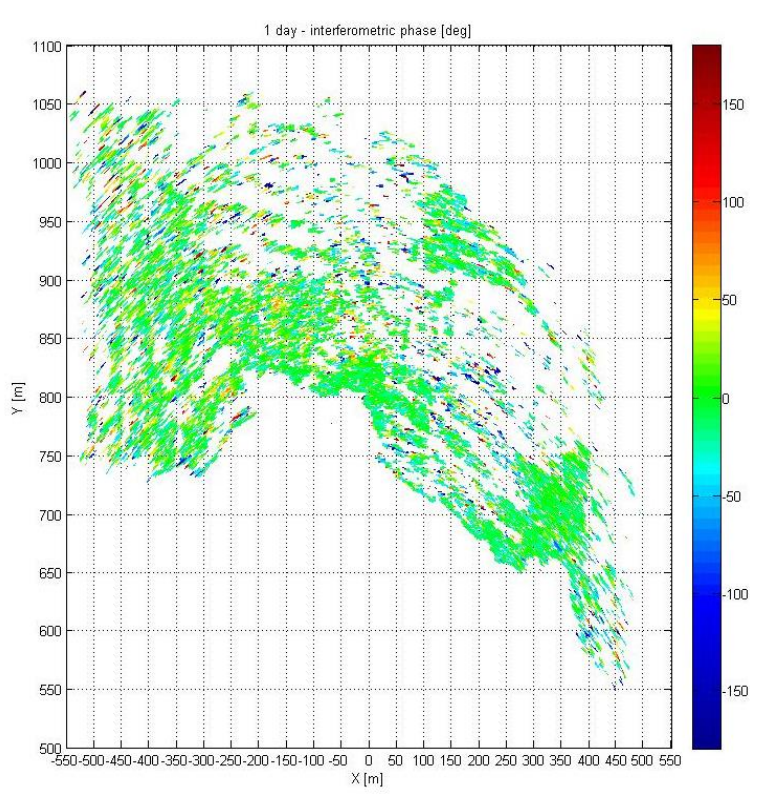

(b)

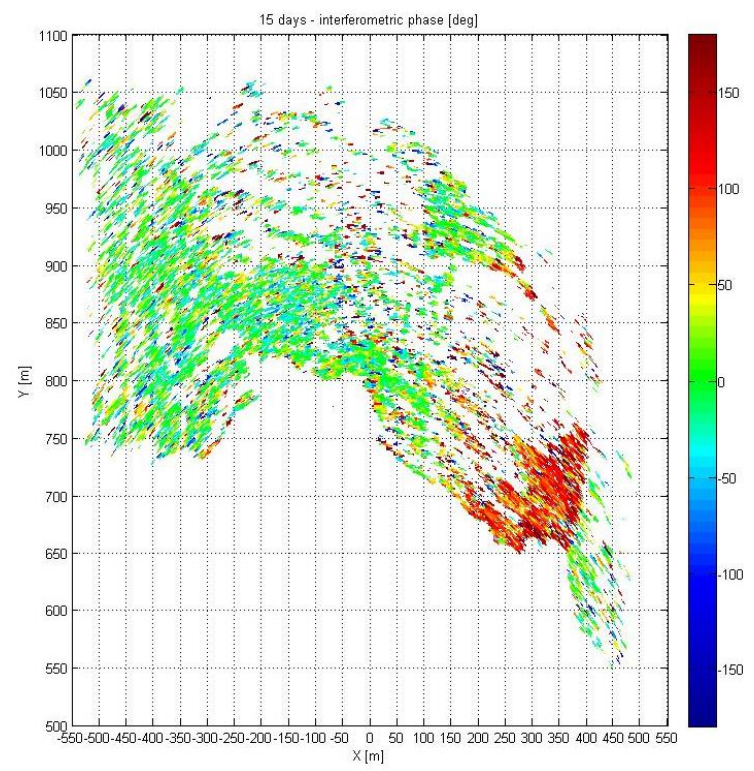

(d)

Figure 1 Interferometric phase over (a) 5 minutes, (b), 1 day, (c) 10 days, and (d) 15 days

From those maps it is clear that the moving areas (yellow and red pixels) can be detected only starting from the interferograms covering a time interval of about 10 days. Unfortunately, since GBInSAR data are based on the measurement of the signal phase, thus being affected by the phase-wrapping phenomenon, computing the interferometric phase on a longer time interval leads to the possibility of missing faster movements. Moreover, a long time intervals between consecutive images typically introduces temporal de-correlation of the radar signal, thus increasing the noise of the displacement measurement. The only way to detect fast and slow movements in a unique real-time processing chain relies in the combination of parallel processing done at different temporal scales.

The authors have developed an algorithm able to process in real time data at different temporal scales (e.g. for fast movements by processing consecutive images acquired every three minutes, then by processing data every 12 hours, 24 hours etc. for slower movements (Figure 2). This new processing chain, called 
'multi-scale', allows automatic and accurate measurement of displacements across four orders of magnitude. The algorithm combines the standard high-performance real-time processing routines for safety critical purposes, with an advanced routine able to track slow moving areas.

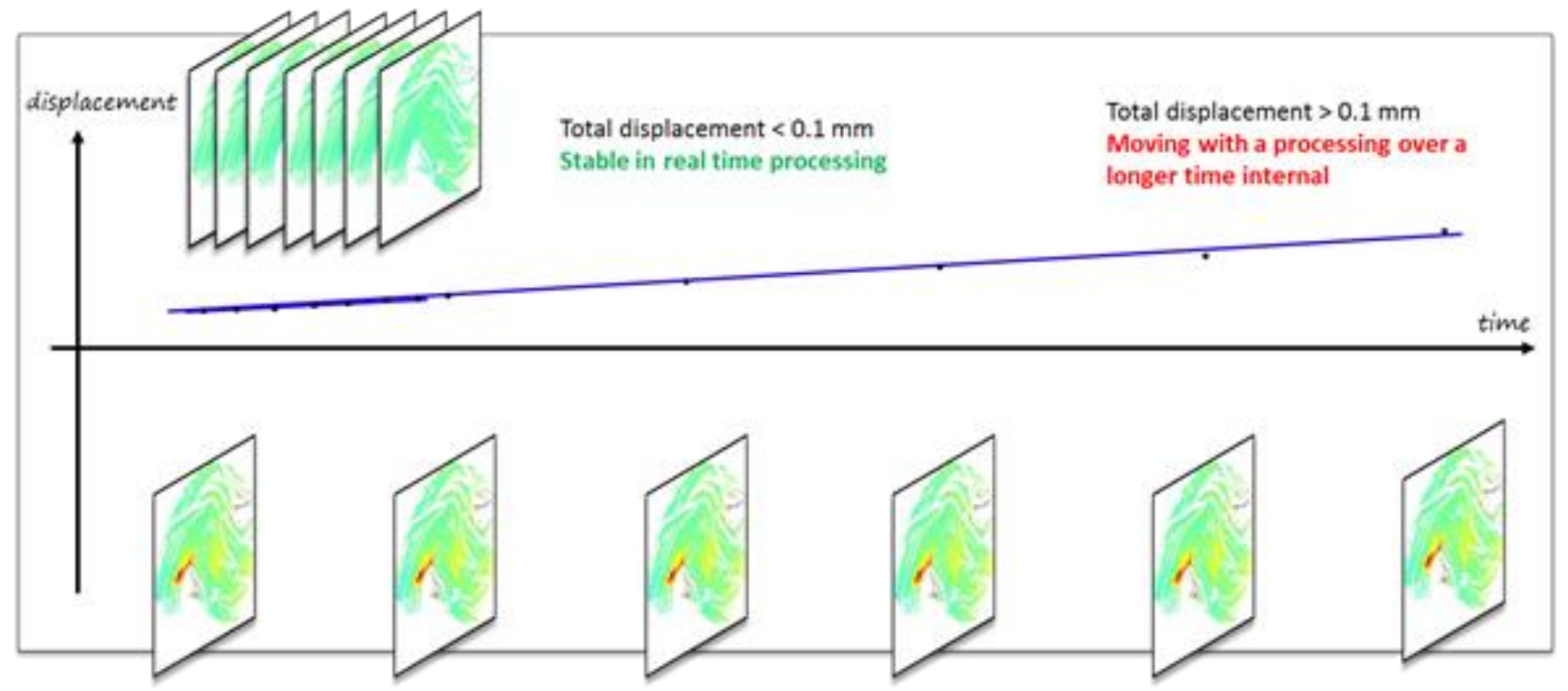

Figure 2 Conceptual scheme of the multi-scale approach

\section{Geological and geotechnical overview of Vale's iron ore mines in the western Iron Quadrangle - Brazil}

Vale's iron south division mines (DIFL) are located in the western part of the Iron Quadrangle (IQ), on the Moeda and Don Bosco Synclines and Curral Homocline ranges as presented in Figure 3. The Iron Quadrangle, located in Minas Gerais State (Brazil), in the southern border of São Francisco Craton is one of the most important mineral provinces of the world and concentrates world class mines of gold, iron and manganese. The structure is delineated by the roughly quadrangular arrangement, with Paleoproterozoic Banded iron Formations (BIF) of the Minas Supergroup, as proposed by United States Department of the Interior (1969). The iron ore host is composed of hundreds of metres of iron ore rich metamorphic rocks. 


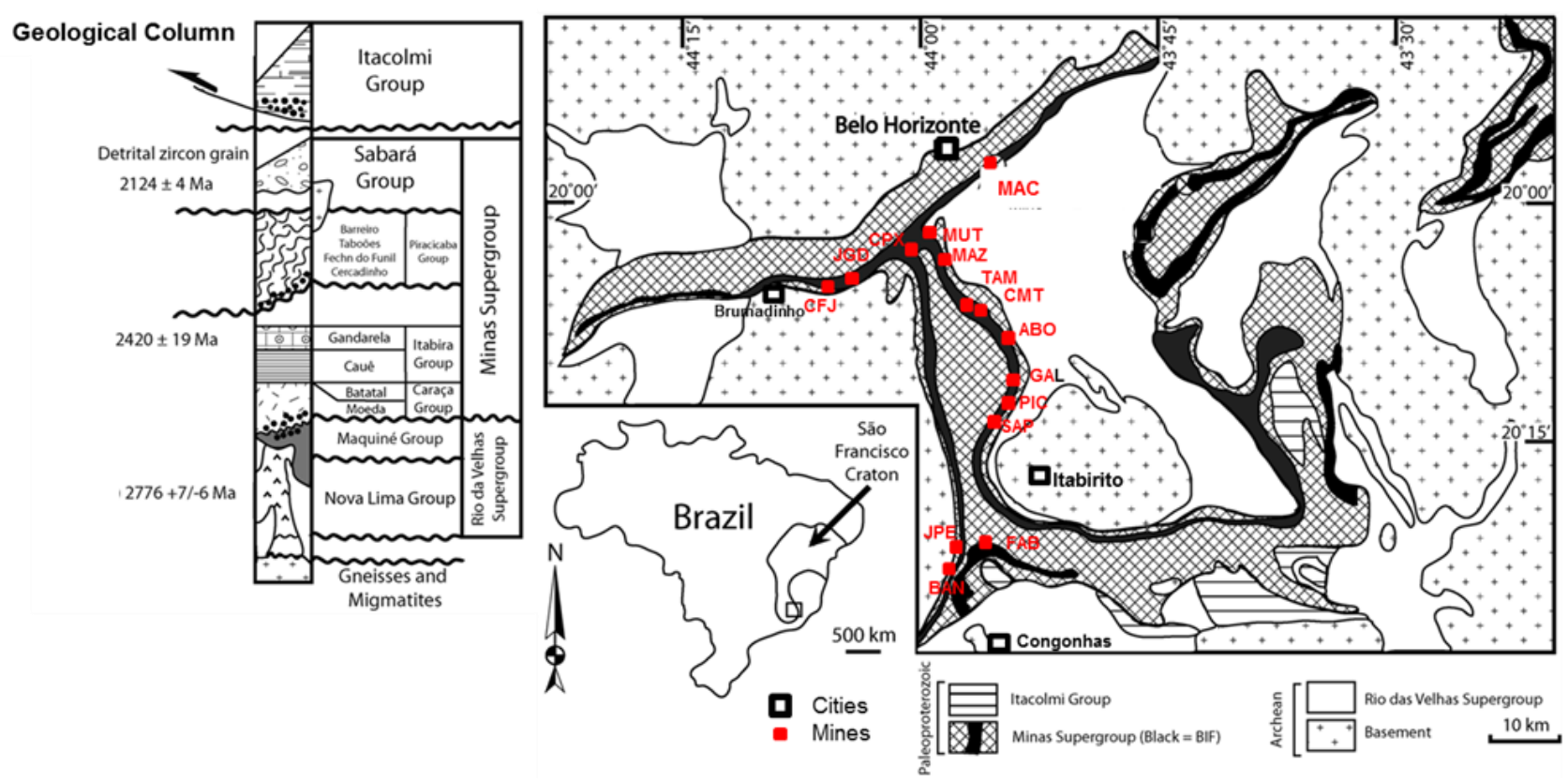

\section{Figure 3 Vale - DIFL mines locations and Iron Quadrangle geological settings} (modified from Morgan et al. 2013)

Usually the mines vary from 200 to $500 \mathrm{~m}$ in depth, covering all possible weathering profiles grades from completely weathered to fresh rock. A typical weathered profile can easily reach $300 \mathrm{~m}$ depth, as often seen in Vale mines. Banding is the most typical characteristic that defines a strong heterogeneity and anisotropy. This banding can be originated by primary sedimentary bedding, tectonic setting, metamorphic grade, hydrothermal or supergene processes (Gross 1980).

In these mines, more than $70 \%$ of exposed slope rocks are weak, with failure mechanisms often controlled by rock mass strength. The weak rocks are susceptible to instability under shear stress mechanisms due to the high stress conditions in the slope toe while instead in hard rocks the primary failure mechanism develops through pre-existing discontinuities.

Therefore, due to the soil mechanics slope behaviour generally observed in the weak rocks and rock mechanics behaviour associated with the hard rocks it is possible to find many types of soil and rock failure mechanisms that can vary in geometry and velocity. The deformation velocities observed in shear stress mechanisms associated with anisotropy or rock heterogeneity and rock failure mechanisms are generally considered fast-moderate ( $\mathrm{mm} /$ day to $\mathrm{mm} / \mathrm{month}$ ), and for shear stress mechanisms associated with the weathered rock mass and high stress conditions are considered slow ( $\mathrm{mm} / \mathrm{months}$ ).

To cover all types of movements an ideal monitoring data acquisition interval must be as close to continuous monitoring as possible to offer more information in shorter periods and to increase the ability to detect slow as well as rapid and unexpected failures. In addition, high accuracy is essential to detect the early stages of movements and increase detection of small failures (Osasan \& Afeni 2010). Regarding this issue Kayesa (2006), cited that an efficient monitoring program has to provide the necessary information to the geotechnical team to identify the security levels, record rock and slope deformation, and involve an accurate timing and precision survey necessary to evaluate and support mining operations to manage slope stability. In relation to time data collection an efficient slope monitoring system needs to be able to detect failures, even small ones, in the early stages of the development in order to give the chance to act with remedies and eventually prevent the failure or reduce the damages. Girard (2001) also pointed out that for safety in mining operations deformation signals must be detected and treated in proper time. 


\section{$4 \quad$ The advantages of including GBInSAR to traditional long-term monitoring systems}

A traditional open pit monitoring system was implemented in Vale's mines using conventional surface and sub-surface sensors such as extensometers, piezometers, water level indicators, visual inspections and prisms measured by a total station (fixed and mobile). The data acquired from these sensors were limited in space and time resulting in some uncertainty about the movements. In 2011 Vale included an IBIS slope monitoring radar in the slope monitoring program to improve the surface monitoring.

The use of radar for long-term monitoring was considered by Vale mines due to the ability of this technology to cover larger areas than those normally monitored by the prisms. These areas are normally monitored using visual inspections alone, and are prone to issues related to meteorological conditions, biased data, and high personal safety risks.

Other advantages for the use of GBInSAR technology for open pit mine long-term monitoring include:

- Reduced number of personnel involved in the acquisition process, including reduced operational risks associated with exposure to unstable conditions.

- Possibility for continuous monitor in all weather conditions.

- High spatial resolution and small percentage of non-coverage areas (shadow).

- Real time processing and ability to integrate with satellite images and prism data.

The data provided by the radar were also used to optimise the use and availability of traditional surveys. It also provides slope images that show zones of low and high risk (according to some velocity thresholds previously defined), thus helping to identify areas that need additional field survey or visual inspections. Another advantage is the possibility to detect the fast velocity displacement. Some drawbacks associated with the use of interferometric radar include:

- Noise produced by strong atmospheric changes and presence of vegetation cover.

- No displacement vector provided only line-of-sight (LOS).

- Mobility and energy supply.

\section{$5 \quad$ Long-term monitoring at Vale mine sites and overcoming with GBInSAR}

Extra efforts between the IDS and Vale team were necessary, especially during the first year of use, to solve the drawbacks in use of the GBInSAR technology for long-term monitoring in Vale mines. Firstly, to solve the mobility and power supply questions the IBIS-FMT trailer was modified in order to meet the Brazilian transport legislation and the triple power supply (solar panel, external electrical source and diesel generator) was used to provide a highly reliable energy supply. A simple excel table was developed to convert the measurements made from the LoS of the radar to the expected direction of the real movement (since all the radars can measure only relative displacements respect to their LoS, approaching or moving away respect to the installation point).

Several Vale sites were used to develop and test the new radar tools and post processing techniques in order to achieve consistent and reliable data acquisition. On one of the sites the radar was able to detect even very slow displacement rates of $0.10-0.15 \mathrm{~mm} /$ day, corresponding to a total cumulative displacement of almost $60-70 \mathrm{~mm}$ during 10 months of monitoring (Figure 4). 


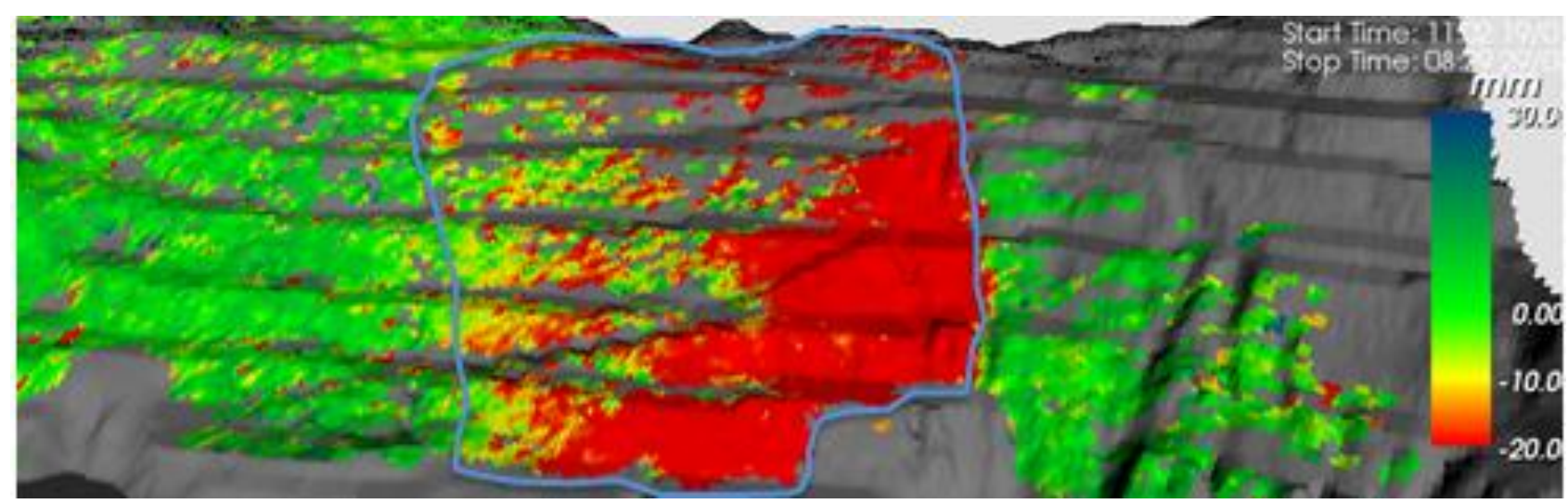

\section{Figure 4 Radar image showing the movement in the first site slope}

For this site, the large amount of vegetation increased the noise level of the radar data. To solve this problem a specific set of post processing routines was established to clarify the temporal and spatial displacement pattern on the pit slopes while subject to very slow movements.

In another site during the rainy season the traditional monitoring system detected areas with velocities varying from 0.5 to $3 \mathrm{~mm} /$ day that reached peaks of $300 \mathrm{~mm} /$ day during high rainfall events. Some adjacent areas presented low velocities $(\mathrm{mm} / \mathrm{month}$ ) as shown in Figure 5. In this period the radar data proved more reliable in comparison with the data acquired by the total station and also provided more overall information. The total station was almost unable to operate during the heavy rainfall. The radar provided velocity data from the moment it commenced operation, and then provided support to the mining operation at the slope toe during the rainy season.

At a third mine site the radar was used to detect slow movements of $0.02 \mathrm{~mm} /$ day slopes with despite the noise produced by the mining operations and vegetation. As presented by Costa et al. (2013), from six months of continuous monitoring, the data obtained by radar, together with data from a number of prisms and crackmeters, were enough to infer the failure mechanism. It also detected other small unstable areas which were previously unnoticed until the radar implementation (Figure 5). The data collected with the radar were compared to those acquired with the total station showing a very good correlation between the two systems (Figure 6). The graph on top presents three months of prism monitoring and the graph on bottom the same deformation history as measured by the radar. The prisms locations are shown as black stars on the image to the right. Even if the amount of total displacement as well as the deformation trend is similar in the two graphs, the radar data results in a smoother graph, due to its higher precision and higher sampling frequency (one measurement every 5 minutes versus one measurement every few hours for the total station). In addition to that, the radar shows a continue coverage of the monitored surface while the total station only provides measurements on discrete isolated points, the three prisms. 


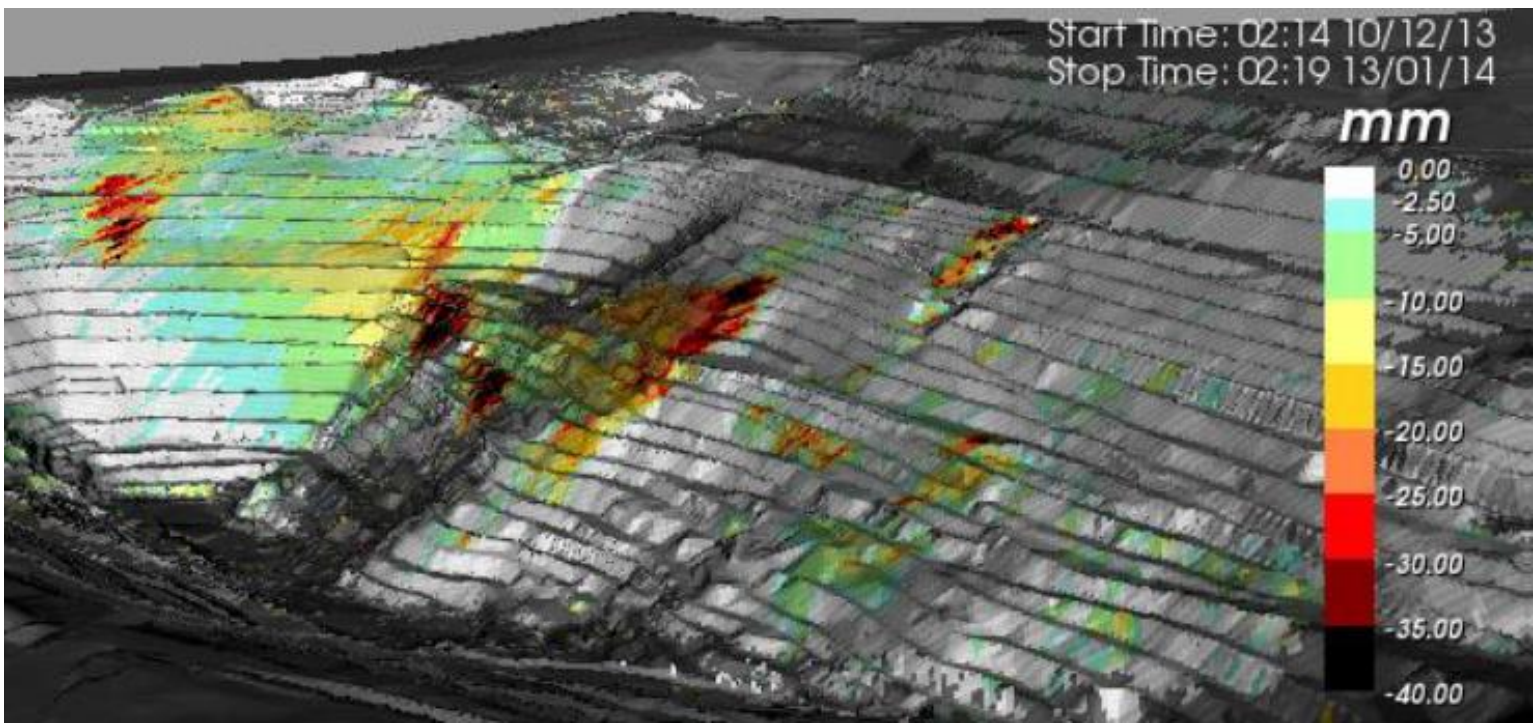

Figure 5 Radar image showing the movement in the second mine

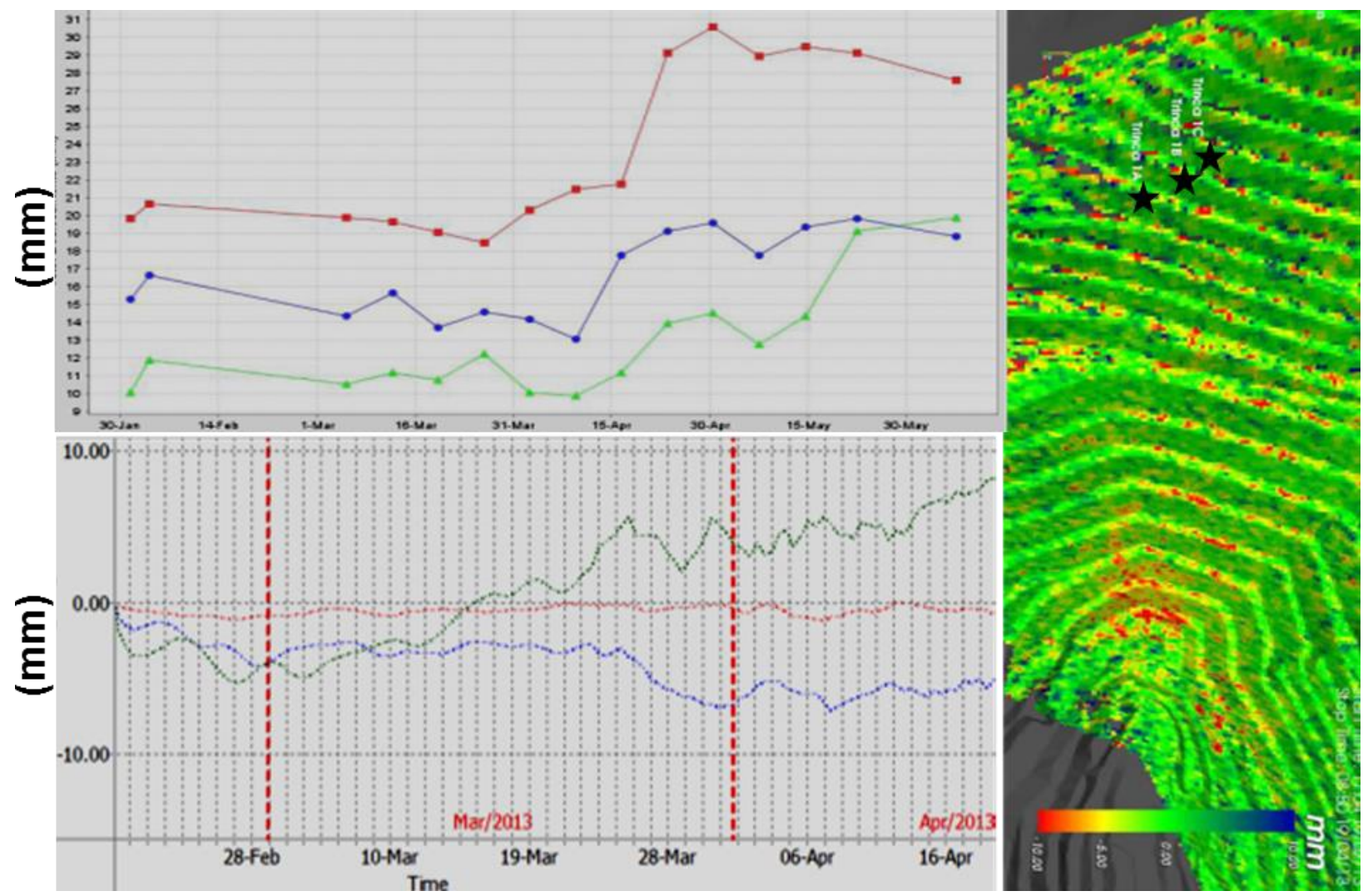

\section{Figure 6 Monitoring data from the third mine site. Comparison of prism and radar monitoring}

\section{Conclusion}

This paper presents the results of advanced data processing algorithms used in some Brazilian Vale S.A. iron ore mines which are able to measure a wide range of displacement rates. In the case studies presented radar data has been integrated and compared to displacement measurements acquired by total stations and other geotechnical instruments, in order to improve the interpretation of the on-going deformations. The use of integrated approaches combining the capabilities of detecting fast and slow movement 
supported by prism and field inspections can lead to the timely detection of slope movements in iron ore mines.

The capability to detect slow movements over large areas of pit walls opens the doors to a new concept of monitoring, which not only presents a valuable tool for safety monitoring of the pit slopes, but also provides a valuable source of information to better understand the slope behaviour before movements start interacting with mining operations.

\section{References}

Antonello, G, Casagli, N, Farina, P, Leva, D, Nico, G, Sieber, AJ \& Tarchi, D 2004, 'Ground based SAR interferometry for monitoring mass movements', Landslides, vol. 1, no. 1, pp. 21-28.

Bozzano, F, Cipriani, I, Mazzanti, P \& Prestininzi, A 2011, 'Displacement patterns of a landslide affected by human activities: insights from ground-based InSAR monitoring', Natural Hazards, vol. 59, no. 3, pp. 1377-1396.

Costa, AT, Costa, TAV, Sayão, AS \& Nunes, ALLS 2013, 'Monitoring of the VALE Córrego do Feijão mine using interferometric radar', Proceedings of the 14th Brazilian Congress of Geology and Environmental Engineering (COBRAE), pp. 120-128.

Farina, P, Coli, N, Yön, R, Eken, G \& Ketizmen, H 2013, 'Efficient real time stability monitoring of mine walls: the Cöllolar Mine case study', Proceedings of the 23rd International Mining Congress and Exhibition of Turkey, pp. 111-117.

Farina, P, Leoni, L, Babboni, F, Coppi, F, Mayer, L \& Ricci, P 2011, 'IBIS-M, an innovative radar for monitoring slopes in open-pit mines', in E Eberhardt \& D Stead (eds), Proceedings of the 11th International Symposium on Rock Slope Stability in Open Pit Mining and Civil Engineering, Canadian Institute of Mining, Metallurgy and Petroleum, Westmount, Quebec, 9 p.

Girard, JM 2001, 'Assessing and monitoring open pit mine highwalls', in FM Jenkins, J Langton, MK McCarter \& B Rowe (eds), Proceedings of the 32nd Annual Institute of Mining Health, Safety and Research, pp. 159-171.

Gross, GA 1980, 'A classification of iron formation based on depositional environments', The Canadian Mineralogist, vol. 18, pp. 215-222.

Kayesa, G 2006, 'Prediction of slope failure at Letlhakane Mine with the Geomos slope monitoring system', Proceedings of the International Symposium on Stability of Rock Slopes in Open Pit Mining and Civil Engineering Situations, Series S44, pp. 605-622.

Morgan, R, Orberger, B, Rosière, CA, Wirth, R, Carvalho, CDM \& Bellver-Baca, MT 2013, 'The origin of coexisting carbonates in banded iron formations: a micro-mineralogical study of the 2.4 Ga Itabira Group, Brazil', Precambrian Research, vol. 224, pp. 491-511.

Osasan, KS \& Afeni, TB 2010, 'Review of surface mine slope monitoring techniques', Journal of Mining Science, vol. 46, no. 2, pp. 177-186.

Pieraccini, M 2013, 'Real beam vs. synthetic aperture radar for slope monitoring', Proceedings of the Progress in Electromagnetics Research Symposium (PIERS), The Electromagnetics Academy, Cambridge, MA, pp. 1627-1632.

United States Department of the Interior 1969, Physiographic, stratigraphic and structural development of the Quadrilátero Ferrifero, Minas Gerais: Geological Survey Professional Paper, prepared by JVN Dorr II, Washington DC. 